\title{
Characterization Of NUClear Microsatellite loci in THE NeOtropical tree Parkia panurensis (FABaceae) ${ }^{1}$
}

\author{
Kathrin Luettmann², Inga M. MichalczyK ${ }^{3}$, Christina Mengel ${ }^{4}$, \\ Birgit Ziegenhagen ${ }^{4}$, Eckhard W. Heymann ${ }^{2}$, Pedro P. Pinedo Saboya ${ }^{5}$, \\ RONALD BIALOZYT ${ }^{4,6}$
}

\begin{abstract}
${ }^{2}$ German Primate Center, Department of Behavioral Ecology and Sociobiology, Kellnerweg 4, 37077 Goettingen, Germany;
${ }^{3}$ Associated with the Philipps-University of Marburg, Faculty of Biology, Conservation Biology, Karl-von-Frisch-Strasse 8, 35032 Marburg, Germany; ${ }^{4}$ Philipps-University of Marburg, Faculty of Biology, Conservation Biology,

Karl-von-Frisch-Strasse 8, 35032 Marburg, Germany; ${ }^{5}$ Facultad de Ciencias Forestales, Universidad

Nacional de la Amazonía Peruana, Pevas 5ta. cuadra, Iquitos, Peru
\end{abstract}

- Premise of the study: We present here a set of nine polymorphic nuclear microsatellite loci, identified for the first time within the neotropical legume tree species Parkia panurensis Benth. ex H. C. Hopkins, which is widespread in western and central Amazonia.

- Methods and Results: To characterize these loci, 33 Parkia panurensis adult trees were analyzed. The number of alleles ranged from eight to 32, with an average of 14.4 alleles per locus. Mean expected heterozygosity ranged from 0.74 to 0.955 .

- Conclusions: All nine loci could also be verified in six other Parkia species and polymorphic fragments amplified. The new marker set can be used for future studies of genetic diversity and differentiation, as well as estimation of gene flow and parentage analyses in various Parkia species.

Key words: cross-species amplification; Parkia species; seed dispersal; simple sequence repeats

Parkia is a tree species belonging to the genus of the legume family Fabaceae and has a pantropical distribution (Hopkins, 1986). One of the Amazonian species of Parkia, P. panurensis Benth. ex H. C. Hopkins, which is distributed over western and central Amazonia in Brazil, Peru, Colombia, and Venezuela (Hopkins, 1986), is a major food resource for the two tamarin species Saguinus mystax and Saguinus fuscicollis (Knogge and Heymann, 2003). In turn, these two primate species act as principal or-in the absence of woolly monkeys (Lagothrix lagothricha) as exclusive seed dispersers for P. panurensis (unpublished data). The latter situation provides the opportunity to study the genetic consequences of seed dispersal in a simplified neotropical model, consisting of one plant and two disperser species. To analyze seed dispersal in $P$. panurensis in ongoing studies, nine nuclear microsatellite loci were identified in this species for the first time and are characterized here. Moreover, assignability to six other Parkia species was tested positively for all loci. These other species are Parkia ingneiflora Ducke, Parkia multijuga Bentham, Parkia nitida Miquel (all from the same location) and Parkia plathycephala Bentham, Parkia bahiae H.C. Hopkins and Parkia pendula (Willdenow) Bentham ex Walpers originating from different locations within South-America.

${ }^{1}$ Manuscript received 9 March 2010; revision accepted 30 March 2010.

This study was carried out with financial support by the German Research Council (DFG) to K. L. (HE 1870/15-1, BI 1070/2-1). We are grateful to INRENA in Lima for the research permit (authorization no. 106-2007-INRENAIFFS-DCB). We thank Piechowski for providing additional samples from Amazonia and Flores Amasifuén and Shahuano Tello for assistance in the field.

6Author for correspondence: bialozyt@staff.uni-marburg.de

doi:10.3732/ajb.1000096

\section{METHODS AND RESULTS}

An enriched library was constructed by ecogenics GmbH (Zurich, Switzerland) from size-selected genomic DNA ligated into SAULA/SAULB-linker (Armour et al., 1994) and enriched by magnetic bead selection with biotinlabeled $(\mathrm{GT})_{13},(\mathrm{CT})_{13},(\mathrm{GCT})_{9}$ and $(\mathrm{CGT})_{8}$ oligonucleotide repeats (Gautschi et al., 2000a; Gautschi et al., 2000b). Of 374 recombinant colonies screened, 166 gave a positive signal after hybridization. Plasmids from 72 positive clones were sequenced, and primers were designed for 20 microsatellite inserts. Amplification products of nine microsatellite markers showed scorable and polymorphic bands after running on an automatic capillary sequencer (MegaBACE 1000, GE Healthcare, Uppsala, Sweden). To characterize the nine confirmed loci, 33 P. panurensis adult trees from one single population at the Estación Biológica Quebrada Blanco in northeastern Peru $\left(4^{\circ} 21^{\prime} \mathrm{S}, 73^{\circ} 09^{\prime} \mathrm{W}\right)$ were genotyped. DNA extraction followed the protocol by Dumolin et al. (1995). As a slight modification, the protocol included an additional final treatment with $0.5 \mu \mathrm{g}$ RNase at $37^{\circ} \mathrm{C}$ for $30 \mathrm{~min}$. PCR reactions were performed in a $25 \mu \mathrm{L}$ volume containing $30 \mathrm{ng}$ of template DNA, $1 \times$ PCR buffer $(5 \times$ buffer Promega, Mannheim, Germany), $0.2 \mu \mathrm{M}$ of each primer (forward primer fluorescence labeled), $0.2 \mathrm{mM}$ of each dNTP, $2.0 \mathrm{mM} \mathrm{MgCl} 2,1$ unit/ $\mu \mathrm{l} \mathrm{GoTaq}$ polymerase (Promega, 5 units $/ \mu \mathrm{l})$ and $0.5 \%$ BSA $(20 \mathrm{mg} / \mathrm{ml})$. The thermal cycler (T1, Biometra, Goettingen, Germany) was programmed with the following conditions: 5 min at $95^{\circ} \mathrm{C}$ for denaturation, followed by 33 cycles at $95^{\circ} \mathrm{C}$ for $45 \mathrm{~s}$, different annealing temperatures ranging from 54 to $60^{\circ} \mathrm{C}$ for $45 \mathrm{~s}$ depending on the specific primer pair used, elongation time at $72^{\circ} \mathrm{C}$ of $40 \mathrm{~s}$ and final extension at $72^{\circ} \mathrm{C}$ for $10 \mathrm{~min}$. Annealing temperatures of the specific primer pairs for best amplification are summarized in Table 1. The PCR amplification products were separated by capillary electrophoresis using the MegaBACE 1000 automated sequencer (GE Healthcare). Alleles were sized using the size standard MegaBACE ET400-R (GE Healthcare) and the MegaBACE Genetic Profiler version 2. Primer labels are reported in Table 1.

Genetic diversity parameters for $P$. panurensis samples were estimated using GenAlEx version 6.2 (Peakall and Smouse, 2006). All nine loci were polymorphic with an average of 14.4 alleles per locus, ranging between eight and 32 (Table 2). Expected heterozygosity ranged from 0.74 to 0.955 with a mean value of 0.803 . Significant deviations from expected heterozygote 
TABle 1. Characteristics of nine nuclear microsatellite loci developed in Parkia panurensis. Shown for each locus is the locus name, the forward (F, fluorescence labeled with HEX, FAM or TAMRA) and reverse (R) primer sequence, the optimized annealing temperature $\left(T_{a}\right)$, the repeat motif, the size range of PCR products in base pairs and the GenBank accession number. Size ranges of the amplified fragments include all fragments discovered within all Parkia species used in this study. For explicit size ranges within a specific Parkia species see Table 2.

\begin{tabular}{|c|c|c|c|c|c|}
\hline Locus & Primer sequence $\left(5^{\prime}-3^{\prime}\right)$ & $T_{a}\left({ }^{\circ} \mathrm{C}\right)$ & Repeat motif & Size range (bp) & GenBank ID \\
\hline Parpan3 & $\begin{array}{l}\text { F: FAM-CACGTTAATTCAATCAAAATGGTG } \\
\text { R: TTTTGCCTTTTCGGACTTG }\end{array}$ & 56.5 & $(\mathrm{GT})_{15}$ & $155-209$ & GU735073 \\
\hline Parpan 4 & $\begin{array}{l}\mathrm{F}: \text { TAMRA-TTGATGGGAGTGGGAAAAAG } \\
\mathrm{R}: \text { CAGGAGGTGGTCTTCAGG }\end{array}$ & 54.0 & $(\mathrm{GT})_{13}(\mathrm{GA})_{15}$ & $148-210$ & GU735074 \\
\hline Parpan5 & $\begin{array}{l}\text { F: FAM-CTCAATAAGATACCCTTTACATTGC } \\
\text { R: TTGAATCGAGGAATGAGATTATTG }\end{array}$ & 60.0 & $(\mathrm{CA})_{17}$ & $166-200$ & GU735075 \\
\hline Parpan 9 & $\begin{array}{l}\text { F: FAM-GGGGCTTGTGTCTCTCACTG } \\
\text { R: ACTTTGAAGGCACGAGATGG }\end{array}$ & 58.0 & $(\mathrm{AC})_{12}$ & $204-262$ & GU735076 \\
\hline Parpan 11 & $\begin{array}{l}\mathrm{F}: \text { HEX-ACGTAGGGAATAGGGCCATC } \\
\mathrm{R}: \text { CTACGTACGAGCCGACACTC }\end{array}$ & 58.5 & $(\mathrm{TG})_{5} \mathrm{CA}(\mathrm{TG})_{16}$ & $94-214$ & GU735077 \\
\hline Parpan 13 & $\begin{array}{l}\mathrm{F}: \text { TAMRA-CCTCCCTCGCTTCACAATC } \\
\mathrm{R}: \text { CACATGCAAATGAAAATGGTG }\end{array}$ & 58.5 & $(\mathrm{GT})_{17} \mathrm{TT}(\mathrm{GT})_{8}$ & $86-194$ & GU735078 \\
\hline Parpan 14 & $\begin{array}{ll}\mathrm{F}: & \text { HEX-ACATCAAAATGGTCGCTCAAC } \\
\mathrm{R}: & \text { CAAATGTTCTTGTATGGAGCAAG }\end{array}$ & 60.0 & $(\mathrm{GT})_{20}$ & $76-116$ & GU735079 \\
\hline Parpan 15 & $\begin{array}{l}\text { F: HEX-TGGCCTCACTGCATACTGAC } \\
\text { R: TGGGATGAACAAAACTGTGC }\end{array}$ & 55.0 & $(\mathrm{AC})_{24}$ & $104-152$ & GU735080 \\
\hline Parpan 21 & $\begin{array}{ll}\mathrm{F}: & \text { HEX-TGCTTTGTGCGACTTGAATC } \\
\mathrm{R}: & \text { CATTGTTCAGCATATAGGCATACAG }\end{array}$ & 58.0 & $(\mathrm{GT})_{15}$ & $153-185$ & GU735081 \\
\hline
\end{tabular}

TABle 2. Results of primer application in seven different Parkia species. The primers were originally developed in Parkia panurensis. For each locus the following informations are shown locus name, number of alleles $\left(N_{a}\right)$, size range of PCR products in base pairs and expected heterozygosity $\left(H_{e}\right)$. The sample size for each species is given in parentheses behind the species name. The second line shows the geographic coordinates of each study site, where the samples came from.

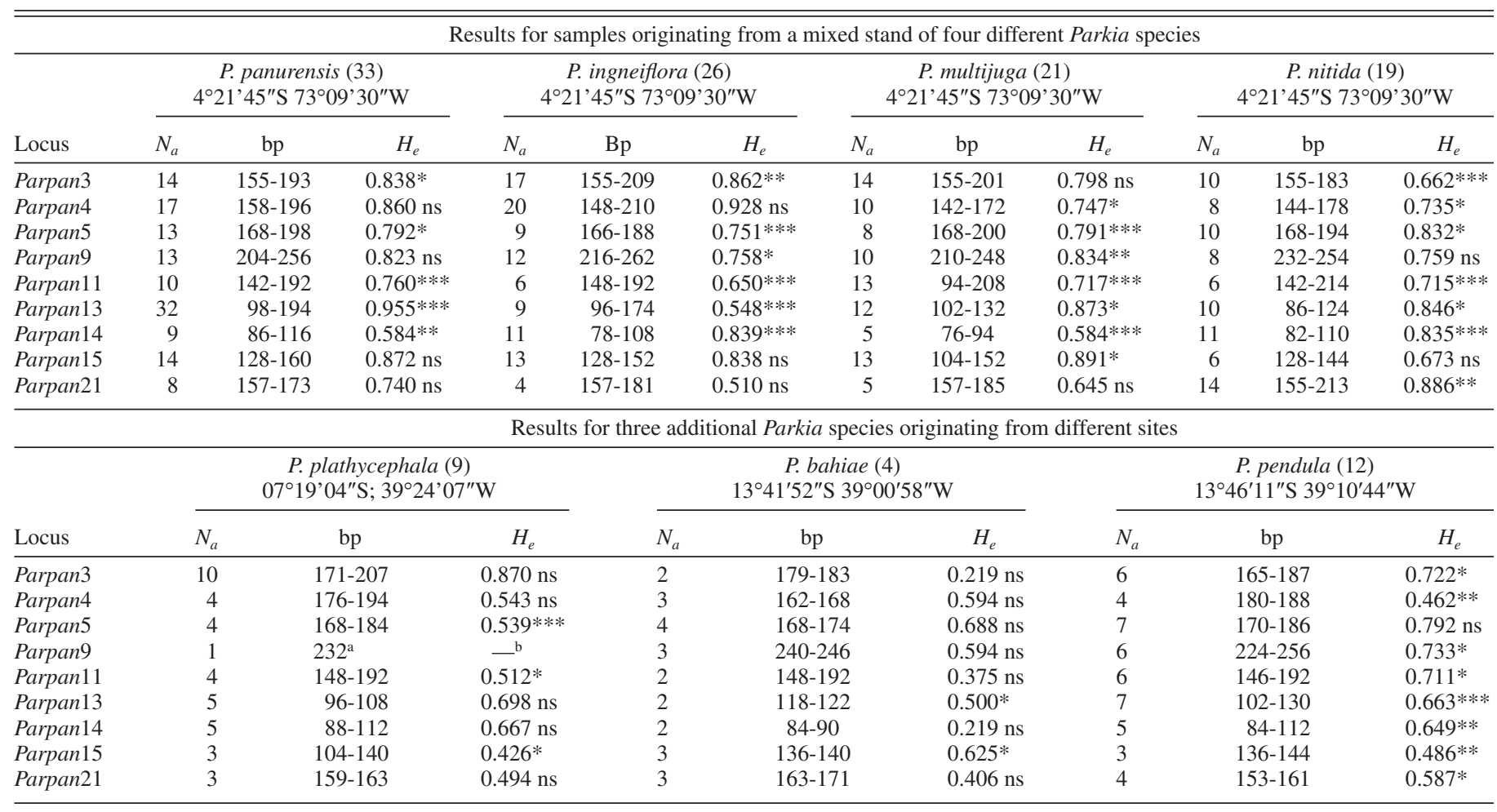

Notes: *, ** and ***: significant departures from Hardy-Weinberg equilibrium at $P<0.05, P<0.01$ and $P<0.001$, respectively.

n.s. = not significant.

aall individuals are homozygous.

${ }^{\mathrm{b}} H_{e}$ cannot be calculated because the marker is monomorph in this species.

frequencies at Hardy-Weinberg equilibrium were observed for Parpan3 and Parpan5 $(P<0.05)$, Parpan14 $(P<0.01)$ and Parpan11 and $13(P<0.001)$.

In an additional step, the newly developed nine microsatellite markers were tested in six other neotropical Parkia species with individual numbers ranging from
4 to 26 (Table 2). Cross-species amplification was found for all nine loci in all tested species. In either case loci were polymorphic and showed amplified DNA fragments of similar sizes compared to $P$. panurensis (Table 2). However, one exception occurred at locus Parpan9 in species $P$. plathycephala, where only one allele 
was found. This might be an effect of the sample size and might disappear in real population genetic studies.

\section{CONCLUSIONS}

In future analyses, the developed microsatellite markers will be used to study small-scale genetic structure as well as seedand pollen-mediated gene flow of various Parkia species in northeastern Peru.

\section{LITERATURE CITED}

Armour, J. A., R. Neumann, S. Gobert, and A. J. Jeffreys. 1994 Isolation of human simple repeat loci by hybridization selection. Human Molecular Genetics 3: 599-605.

Dumolin, S., B. Demesure, and R. J. Petit. 1995. Inheritance of chloroplast and mitochondrial genomes in pedunculate oak investigated with an efficient PCR method. Theoretical and Applied Genetics 91: $1253-1256$.

Gautschi, B., I. Tenzer, J. P. Müller, And B. Schmid. 2000a. Isolation and characterization of microsatellite loci in the bearded vulture (Gypaetus barbatus) and cross-amplification in three Old World vulture species. Molecular Ecology Notes 9: 2193-2195.

Gautschi, B., A. Widmer, AND J. Koella. 2000b. Isolation and characterization of microsatellite loci in the dice snake (Natrix tessellata) Molecular Ecology Notes 9: 2191-2193.

Hopkins, H. C. 1986. Parkia (Leguminosae: Mimosoideae). Flora Neotropica 43: 1-123.

Knogge, C., and E. W. Heymann. 2003. Seed dispersal by sympatric tamarins, Saguinus mystax and Saguinus fuscicollis: diversity and characteristics of plant species. Folia Primatologica 74: $33-47$.

Peakall, R., and P. E. Smouse. 2006. GENALEX 6: genetic analysis in Excel. Population genetic software for teaching and research. Molecular Ecology Notes 6: 288-295. 